\title{
MANAGEMENT OF COTTON BUD INDUCED OTITIS EXTERNA BY UNIQUE METHOD
}

\author{
Syed Muhammad Asad Shabbir Bukhari, Sohail Aslam, Naeem Riaz, Muhammad Waqas Ayub*, Irfan Saeed**, Adnan Asghar, \\ Muhammad Fahad Wasim Khan \\ Pakistan Naval Ship Shifa Hospital, Karachi Pakistan, *Combined Military Hospital Okara/National University of Medical Sciences (NUMS) Pakistan, \\ ${ }^{* *}$ Combined Military Hospital Abbottabad/National University of Medical Sciences (NUMS) Pakistan
}

\section{ABSTRACT}

Objective: To compare the recovery of patients in both groups having acute otitis externa induced by cotton buds/various objects. One group by old method and second group by unique method.

Study Design: Quasi-experimental study.

Place and Duration of Study: Pakistan Naval Ship Shifa Karachi, from Jan to Dec 2020.

Methodology: Non-probability convenience sampling technique was applied. Out of 50 cases were selected for group 1 management. Fifty cases were selected for group 2 management. A chi-square test was applied to compare the recovery of two groups of patients on the $14^{\text {th }}$ day and $42^{\text {nd }}$ day of follow-up. $p$-value was kept 0.05 as significant.

Results: A total of 100 cases were treated in 2 groups. The gender distribution of the study was 54 females and 46 males. The mean age of the study population was $33.09 \pm 12.93$ years. $p$-value was calculated on the $14^{\text {th }}$ day and $42^{\text {nd }}$ days. A $2 \times 2$ table of $14^{\text {th }}$ follow up day showed recovery by both groups with a $p$-value of 0.041 which is $<0.05$. This showed that group 2 management was statistically better than group 1 management.

Conclusion: The second group was managed with eardrops containing Betamethasone and Neomycin. This management protocol is unique and better than conventional management as done in the first group.

Keywords: Cotton bud induced otitis externa, Management, Strict advice, Unique method.

How to Cite This Article: Bukhari SMAS, Aslam S, Riaz N, Ayub MW, Saeed I, Asghar A, Khan MFW. Management of Cotton Bud Induced Otitis Externa by Unique Method. Pak Armed Forces Med J 2021; 71(Suppl-3): S448-451. D Doi: https://doi.org/10.51253/pafmj.v1i1.7943

This is an Open Access article distributed under the terms of the Creative Commons Attribution License (https://creativecommons.org/licenses/by-nc/4.0/), which permits unrestricted use, distribution, and reproduction in any medium, provided the original work is properly cited.

\section{INTRODUCTION}

Acute otitis externa induced by the self-ear cleaning habit of the general population with cotton buds is a very common ear disease. Acute otitis media may present with the severity of mild, moderate, and severe. Mild severity of acute otitis externa is strongly associated with the use of cotton buds. ${ }^{1,2}$ Acute otitis externa of mild severity is managed with various otolaryngologists by multiple methods. Management should be explained by experienced otolaryngologists to the patients and young doctors for the improvement of patient care. Itching, urge to scratch the ear canals with a cotton bud or various objects and mild pain are the main symptoms of this very common ear disease. On examination, mild erythema and scratch marks are seen on the skin of the external ear canal. Management includes topical ear drops containing steroids and antibiotics and oral analgesics for few days. Recurrence of acute otitis externa is very common due to the lack of strict preventive advice and strategy to control their urge to scratch the ears with various objects. Two groups of patients were managed in this study with acute otitis externa mild severity and cotton bud/various

Correspondence: Dr Syed Muhammad Asad Shabbir Bukhari, Classified ENT Specialist, PNS Shifa, Rawalpindi Pakistan objects usage habit in ears. One group was managed with the ear drops containing Polymyxin B, Neomycin, and Hydrocortisone. These drops were advised as 3 drops 4 times a day for 7 days and patients were given soft advice to stop using any objects for ear-cleaning. The second group was managed with eardrops containing Betamethasone and Neomycin. The patients were given strict advice to stop using any objects for earcleaning and these 3 drops can be put from 5-12 times a day in the ears. The patients should control themselves from self-cleaning ears and can put 3 ear drops to control their urge to scratch. These drops can be used for few months on and required basis. Both groups of patients have been given Tablet Loratadine $10 \mathrm{mg}$ once daily for 7 days along with oral analgesic according to pain score. The difference between both treatments is shown in Table-I.

The purpose of this study was to compare the recovery of patients in both groups having acute otitis externa induced by cotton buds/various objects. One group by old method and second group by unique method.

\section{METHODOLOGY}

This was a quasi-experimental study that was conducted in Pakistan Naval Ship Shifa Karachi, from 
January to December 2020. Ethical approval from the institutional review committee was taken. A non probability convenience sampling technique was applied. Fifty cases were selected for the group 1 management protocol. One group was managed with ear drops containing Polymyxin B, Neomycin, and hydrocortisone. These drops were advised as 3 drops 4 times a day for 7 days and patients were given soft advice to stop using any objects for ear-cleaning. Fifty cases were selected for the group 2 management protocol. The second group was managed with ear drops containing Betamethasone and Neomycin. The patients were given strict advice to stop using any objects for ear-cleaning and these 3 drops can be put from 5-12 times a day in the ears. The patients should control themselves from self-cleaning ears and can put 3 ear drops to control their urge to scratch.

Inclusion Criteria:A 100 cases of acute otitis externa induced by cotton bud self-ear cleaning habit were included in the study after taking history and performing an examination.

Exclusion Criteria: Patients having moderate severity acute otitis externa, chronic suppurative otitis media, otomycosis, and age $<15$ years were excluded. Recovery was determined by follow-up visits of the patients and a chi-square test was applied to compare the recovery of two groups of patients on the $14^{\text {th }}$ day and $42^{\text {nd }}$ day of follow up. $p$-value was kept 0.05 as significant. Frequencies, standard deviation, and mean were calculated by using descriptive statistics of SPSS-20.

\section{RESULTS}

A total of 100 cases were treated in 2 groups. The gender distribution of the study was 54 females and 46 males. The gender distribution is shown in Figure-1. The mean age of the study population was $33.09 \pm 12.93$ years. The minimum age is 15 years and the maximum age is 58 years. $p$-value was calculated on the $14^{\text {th }}$ day and $42^{\text {nd }}$ days by applying chi square test and using SPSS-20.

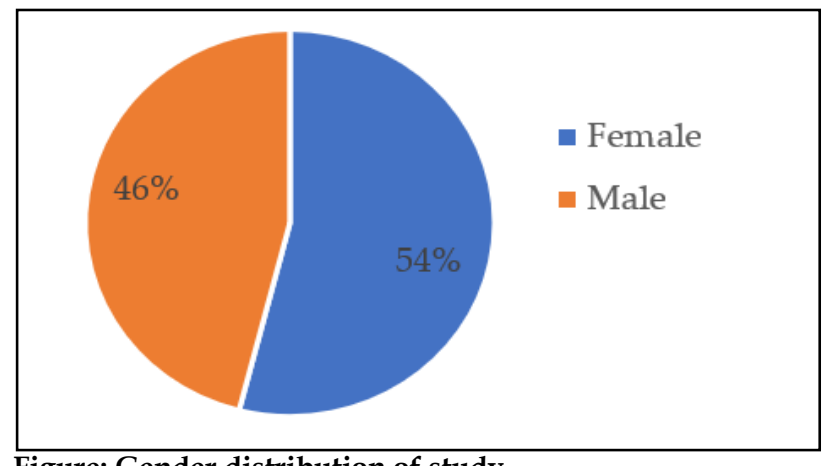

Figure: Gender distribution of study.
A $2 \times 2$ table of $14^{\text {th }}$ follow day showed recovery by both groups with a $p$-value of 0.041 which is less than 0.05. This is shown in Table-II. This showed that group 2 management was statistically better than group 1 management. $2 \times 2$ table of $42^{\text {nd }}$ follow up day showed recovery of both groups with a $p$-value of 0.001 . This is depicted in Table-III. This showed that the management protocol of group 2 was highly statistically significant and better than the treatment of the group-1.

Table-I: Difference between two treatments.

\begin{tabular}{l|c}
\hline Treatment $\mathbf{1}$ (old) & $\begin{array}{c}\text { Treatment } \mathbf{2} \text { (Unique } \\
\text { Method) }\end{array}$ \\
\hline $\begin{array}{l}\text { Soft advice to quit using } \\
\text { objects in ears }\end{array}$ & $\begin{array}{c}\text { Strict advice to quit using } \\
\text { objects in ears }\end{array}$ \\
\hline Short duration (1-2 weeks) & Long duration (1-2 months) \\
\hline No counselling & $\begin{array}{c}\text { Counselling on dangerous } \\
\text { habit and its adverse health } \\
\text { hazards, was given }\end{array}$ \\
\hline $\begin{array}{l}\text { No habit controlling } \\
\text { advice and medication }\end{array}$ & $\begin{array}{c}\text { Habit controlling advice with } \\
\text { medication (03 ear drops 12-14 } \\
\text { times / day) was given. }\end{array}$ \\
\hline $\begin{array}{l}\text { Topical eardrops (2 } \\
\text { antibiotics and one steroid } \\
\text { combination) }\end{array}$ & $\begin{array}{c}\text { Topical ear drops (1 antibiotic } \\
\text { and } 1 \text { different steroid } \\
\text { combination) }\end{array}$ \\
\hline
\end{tabular}

Table-II: $2 \times 2$ table at 14 th follow up day showing recovery of both group cases $(n=100)$.

\begin{tabular}{|c|c|c|c|c|}
\hline \multirow{2}{*}{\multicolumn{2}{|c|}{ Disease Outcome }} & \multicolumn{2}{|c|}{ Groups } & \multirow{3}{*}{$\begin{array}{c}\text { Total } \\
86 \\
\end{array}$} \\
\hline & & \multirow{2}{*}{$\begin{array}{c}\text { Group 1 } \\
39\end{array}$} & \multirow{2}{*}{$\frac{\text { Group } 2}{47}$} & \\
\hline \multirow{2}{*}{ Recovery } & Recovered & & & \\
\hline & Not recovered & 11 & 3 & 14 \\
\hline \multicolumn{2}{|l|}{ Total } & 50 & 50 & 100 \\
\hline
\end{tabular}

Table-III: $2 \times 2$ table at 42 nd follow up day showing recovery of both group cases $(n=100)$.

\begin{tabular}{|c|c|c|c|c|}
\hline \multirow{2}{*}{\multicolumn{2}{|c|}{ Disease Outcome }} & \multicolumn{2}{|c|}{ Groups } & \multirow{3}{*}{$\begin{array}{c}\text { Total } \\
80 \\
\end{array}$} \\
\hline & & \multirow{2}{*}{$\begin{array}{c}\text { Group } 1 \\
33\end{array}$} & \multirow{2}{*}{$\frac{\text { Group } 2}{47}$} & \\
\hline \multirow{2}{*}{ Recovery } & Recovered & & & \\
\hline & Not recovered & 17 & 3 & 20 \\
\hline Total & & 50 & 50 & 100 \\
\hline
\end{tabular}

\section{DISCUSSION}

Acute otitis externa induced by cotton budlike objects is a very important clinical disease and its proper management should be discussed in recent research. Unfortunately, this disease was treated under a variety of acute inflammatory or infective diseases of the external ear. Few authors discussed the disease as swimmer's ear. ${ }^{1}$ Few scholars explained the guidelines to manage in articles and books. Few randomized clinical trials were done. Most of the management was related to infective etiological factors of otitis externa. Cotton bud-induced otitis externa has a strong association 
with contact dermatitis, neurodermatitis, and urge to scratch the ears. ${ }^{2}$ The management must include strict advice to stop self-ear cleaning and a long-term strategy to control the urge to clear the ears. Another misleading information of the general public of the world is the beneficial effects of the use of cotton buds in ears like personal hygiene of children, ${ }^{3}$ removal of wax, and reduction in itching. Our study supported itching and wax removal as the major reasons for cotton bud use. This wrong thinking should be properly discouraged by doctors to save the cotton bud-induced ear diseases in the masses. The personal hygiene of self and children, itching reduction, and wax removal were the leading reasons for using cotton buds reported from other studies. ${ }^{4-6}$ Our study supported itching and wax removal as the major reasons for cotton bud use, but these reasons must be negated by doctors in strict quitting advice of self-ear cleaning habit by patients. ${ }^{7}$

This study is the first to disseminate the knowledge about the serious involvement of doctors with their patients and guiding them to live healthy lives by quitting bad ear self-cleaning habits. Management protocol for group 1, is based on the author's experience of treating the patients in the majority of ENT outdoor clinics of the world. 8,9 This management is not addressing the habit modification, strategies, and motivation of the patients in case of an urge to scratch the ear. Management protocol for group 2, is adopted by the author after performing a pilot project study on cotton bud-induced otitis externa patients. The $p$-values were calculated at $14^{\text {th }}$ to follow up and $42^{\text {nd }}$ follow up days. The results of this study are very clear and giving a message of successful management by group 2 protocol. On the $14^{\text {th }}$ follow day, the $p$-value was 0.04 which was less than 0.05 . It means that initial recovery was better with the management protocol of the group 2 . However, the situation was clearer on the $42^{\text {nd }}$ day of the follow-up visit. $p$-value was 0.001 and was highly significant statistically. The patients did not control their habits of self-ear cleaning in group 1 and the recovery rate was dropped. Only a few patients in group 2 could not control their self-ear cleaning habit as the bad habits usually tend to quit with difficulties. Randomized clinical trials should be done in the future for collecting more evidence-based medical practice. Cotton buds and various objects like keys, fingers, match sticks, and hair pins are very injurious for self-ear cleaning. These objects causes wax impaction, ear wounds, acute otitis externa, neurodermatis, ${ }^{10}$ contact dermatitis, perichondritis of the external ear, foreign body external ears and tympanic membrane perforation. ${ }^{11-16}$
Adegbiji et al observed the commonest object used in ear cleaning was cotton bud, ${ }^{17}$ In our study, a cotton bud was the most popular in cases. In all patients with external ear disease, proper history of self-ear cleaning must be taken by every ENT specialist. All those patients who have such dangerous habits must be identified and should be treated immediately or 1 weeks after treating primary disease, with management protocol of group 2 of this study. This management requires regular follow-up visits along with counseling of treating doctors regarding quitting self-ear cleaning habits. The use of ear drops containing Betamethasone and Neomycin is very safe in patients with intact tympanic membrane and can be put on the skin of the external ear more than 12 times a day with minimal absorption in the blood. These drops are the saviors for the patients to control their urge to scratch ears. Prolong use of these drops have no adverse effects because, after 7 days, the majority of patients use them less than 5 times a day and put them on a required basis only. Few exceptional patients cannot control their urge to scratch ears even after using steroid ear drops. These patients are advised to use steroid-based skin ointment at the outer one-third of the skin of the external ear with a clean little finger twice daily for 7 days. These various methods with oral anti-allergic medication lead to success in the majority of patients and reduce the burden of such diseases in ENT outdoor clinics in the future.

The awareness of medical students and young doctors regarding cotton bud-induced ear diseases is very important. Few studies showed that the majority of medical personnel were ignorant of this bad habit. 18,19 Few studies showed the same attitude from the general public with high literacy. ${ }^{20,21}$ Young doctors usually manage the referral to ENT outdoor at primary health care centers and general practitioners in various countries. All these doctors must follow this unique method for management of cotton bud induced acute otitis externa as we treated group 2. This protocol will alleviate masses of the world population from preventable external ear diseases. They can treat a large number of patients after taking history, identifying habits of self-ear cleaning, and otoscopy. They can manage with more confidence and motivation by giving time to their patients. This simple and effective management should be taught to medical students under graduation level at medical colleges. Awareness of cottonbudrelated complications is an important public health issue. Safer methods of aural toileting and suction may also need supporting, 22 by doctors. 


\section{ACKNOWLEDGEMENT}

We are thankful to our parents, teachers and friends.

\section{LIMITATION OF STUDY}

The study was conducted in limited number of patients. This study should be done globally as the habit of cleaning ears is ubiquitous .

\section{CONCLUSIONS}

The second group was managed with eardrops containing Betamethasone and Neomycin. The patients were given strict advice to stop using any objects for ear-cleaning and these 3 drops can be put from 5-12 times a day in-ears to control their urge to scratch the ears. This management protocol is unique and better than conventional management as done in the first group. Young doctors must learn this management protocol to serve humanity in a better manner. Awareness of cotton-bud-related complications is an important public health matter. Safer methods of aural toileting and suction may also need promoting by doctors.

\section{Conflict of Interest: None.}

\section{Authors' Contribution}

SMASB: Conception of Work, SA: Data collection, NR: Data analysis, MWA: Writing of introduction, IS: Critical revision, AA: Discussion writing, MFWH: Literature review.

\section{REFERENCES}

1. Nussinovitch M, Rimon A, Volovitz B, Raveh E, Prais D, Amir J. Cotton-tip applicators as a leading cause of otitis externa. Inter JPediat Otorhinolaryngol 2004; 68(4): 433-435.

2. Ahmed S, Zaheer SA, Shabbir SM, Rao S, Islam T, Ahmed B. Association of dermatological conditions of external ear with the use of cotton buds. J Enam Med Coll 2014; 4(2):174-176.

3. Adegbiji WA, Aremu SK, Olatoke F, Olajuyin AO, Ogundipe KO. Epidemiology of otitis externa in a developing country. Inter J Recent Sci Res 2017;8(6):18023-18027.

4. Afolabi AO, Kodiya AM, Bakari A, Ahmad BM. The attitude of self ear cleaning in black Africans: any benefit?. East Afri JPublic Health 2009; 6(1): 1-5.

5. Adegbiji WA, Alabi BS, Olajuyin OA, Nwawolo CC. Earwax impaction: symptoms, predisposing factors, and perception among nigerians. J Family Med Prim Care 2014; 3(1): 379-382.

6. Lee LM, Govindaraju R, Hon SK. Cotton bud and ear cleaning-A loose tip cotton bud?. Med J Malaysia 2005; 60(1): 85-88.

7. Robertson MS. The misuse of cotton wool buds. The New Zeal Med J 1972; 75(476): 37-40.
8. Wiegand S, Berner R, Schneider A, Lundershausen E, Dietz A. Otitis externa: investigation and evidence-based treatment. Deut Ärzteblatt Inter 2019; 116(13): 224-228.

9. Adegbiji WA, Aremu SK, Olatoke F, Olajuyin AO, Ogundipe $\mathrm{KO}$. Epidemiology of otitis externa in a developing country. Inter J Recent Sci Res 2017; 8(6):18023-18027.

10. Brobby GW. The discharging ear in the tropics: a guide to diagnosis and management in the district hospital. Tropical Doct 1992; 22(1):10-13.

11. Smith M, Darrat I, Seidman M. Otologic complications of Q-tip use: one institution's experience. Laryng 2012; 122(2): 409-411.

12. Kennedy CTC. The external ear. In: Burns T, Breathnach S, Cox N, Griffiths C (eds). Rook's textbook of dermatology. 8th edn. United Kingdom: Wiley Blackwell 2010; 4(2): 27-64.

13. Loock JW. Perichondritis of the external ear. In: Browning GG, Burton MJ, Clarke R, Hibbert J, Jone NS, Lund VJ, Luxon LM, Watkinson JC (eds). Scot-Brown's otorhinolaryngology: head and neck surgery (vol 2). 7th edn. Great Britain: Hodder Arnold 2008;1(1): 3358-3361.

14. Loock JW. Benign nectrotizing otitis externa. In: Browning GG, Burton MJ, Clarke R, Hibbert J, Jone NS, Lund VJ, Luxon LM, Watkinson JC (eds). Scot-Brown's otorhinolaryngology: head \& neck surgery. 7th edn. Great Britain: Hodder Arnold 2008;2(1): 3332-3335.

15. Kumar S, Ahmed S. Use of cotton buds and its complications. J Surg Pak Inter 2008; 13(3): 137-138.

16. Amutta SB, Yunusa MA, Iseh KR, Obembe A, Egili E, Aliyu D, et al. Sociodemographic characteristics and prevalence of self-ear cleaning in Sokoto Metropolis. Inter J Otolaryngol Head Neck Surg 2013; 2(1): 276-279.

17. Adegbiji WA, Olajide TG, Nwawolo CC. Patterns of Self Ear Cleaning among Otorhinolaryngology Patients in Developing Country. Asian J Sci Technol 2018; 9(4): 1-5.

18. Gadanya M, Abubakar S, Ahmed A, Maje AZ. Prevalence and attitude of self-ear cleaning with cotton bud among doctors at aminu Kano teaching hospital, Northwestern Nigeria. Niger J Surg Res 2016; 17(2): 43-45.

19. Alshehri AA, Asiri KA, Saeed M, Alahmari D, Alwabel $\mathrm{HH}$ Alahmari YD, et al. Knowledge, attitudes, and practices of selfear cleaning among medical and non-medical students at King Khalid University, Abha, Saudi Arabia. Int J Med Dev Ctries 2020; 4(6): 960-967.

20. Khan NB, Thaver S. Self-ear cleaning practices and the associated risk of ear injuries and ear-related symptoms in a group of university students. J Pub Health Africa 2017; 8(2): 1-5.

21. Hobson JC, Lavy JA. Use and abuse of cotton buds. J Royal Soc Med 2005; 98(8): 360-361.

22. Nagala S, Singh P, Tostevin P. Extent of cotton-bud use in ears. British J General Pract 2011; 61(592): 662-663. 